University of Nebraska - Lincoln

DigitalCommons@University of Nebraska - Lincoln

Nebraska Cooperative Fish \& Wildlife Research Nebraska Cooperative Fish \& Wildlife Research Unit -- Staff Publications

2014

\title{
Discontinuities, cross-scale patterns, and the organization of ecosystems
}

\author{
Kirsty L. Nash \\ James Cook University, nashkirsty@gmail.com \\ Craig R. Allen \\ University of Nebraska-Lincoln, callen3@unl.edu \\ David G. Angeler \\ Swedish University of Agricultural Sciences, david.angeler@slu.se \\ Chris Barichievy \\ Ezemvelo KZN Wildlife \\ Tarsha Eason \\ U.S. Environmental Protection Agency
}

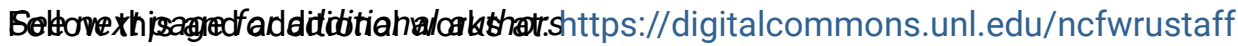

Part of the Aquaculture and Fisheries Commons, Environmental Indicators and Impact Assessment Commons, Environmental Monitoring Commons, Natural Resource Economics Commons, Natural Resources and Conservation Commons, and the Water Resource Management Commons

Nash, Kirsty L.; Allen, Craig R.; Angeler, David G.; Barichievy, Chris; Eason, Tarsha; Garmestani, Ahjond S.; Graham, Nicholas A. J.; Granholm, Dean; Knutson, Melinda; Nelson, R. John; Nyström, Magnus; Stow, Craig A.; and Sundstrom, Shana M., "Discontinuities, cross-scale patterns, and the organization of ecosystems" (2014). Nebraska Cooperative Fish \& Wildlife Research Unit -- Staff Publications. 133. https://digitalcommons.unl.edu/ncfwrustaff/133

This Article is brought to you for free and open access by the Nebraska Cooperative Fish \& Wildlife Research Unit at DigitalCommons@University of Nebraska - Lincoln. It has been accepted for inclusion in Nebraska Cooperative Fish \& Wildlife Research Unit -- Staff Publications by an authorized administrator of DigitalCommons@University of Nebraska - Lincoln. 


\section{Authors}

Kirsty L. Nash, Craig R. Allen, David G. Angeler, Chris Barichievy, Tarsha Eason, Ahjond S. Garmestani, Nicholas A. J. Graham, Dean Granholm, Melinda Knutson, R. John Nelson, Magnus Nyström, Craig A. Stow, and Shana M. Sundstrom 


\title{
Discontinuities, cross-scale patterns, and the organization of ecosystems
}

\author{
Kirsty L. Nash, ${ }^{1,13}$ Craig R. Allen, ${ }^{2}$ David G. Angeler, ${ }^{3}$ Chris Barichievy, ${ }^{4,5}$ Tarsha Eason, ${ }^{6}$ \\ Ahjond S. Garmestani, ${ }^{6}$ Nicholas A. J. Graham, ${ }^{1}$ Dean Granholm, ${ }^{7}$ Melinda Knutson, ${ }^{8}$ R. John Nelson, ${ }^{9}$ \\ Magnus Nyström, ${ }^{10}$ Craig A. Stow, ${ }^{11}$ and Shana M. Sundstrom ${ }^{12}$ \\ ${ }^{1}$ ARC Centre of Excellence for Coral Reef Studies, James Cook University, Townsville, Queensland 4811 Australia \\ ${ }^{2}$ U.S. Geological Survey-Nebraska Cooperative Fish and Wildlife Research Unit, University of Nebraska, \\ Lincoln, Nebraska 68583 USA \\ ${ }^{3}$ Swedish University of Agricultural Sciences, Department of Aquatic Sciences and Assessment, Uppsala SE-75007 Sweden \\ ${ }^{4}$ Ezemvelo KZN Wildlife, Ithala Game Reserve, Louwsberg 3150 South Africa \\ ${ }^{5}$ Centre for African Ecology, University of Witwatersrand 2050, Johannesburg, South Africa \\ ${ }^{6}$ U.S. Environmental Protection Agency, National Risk Management Research Laboratory, Cincinnati, Ohio 45268 USA \\ ${ }^{7}$ U.S. Fish and Wildlife Service, Bloomington, Minnesota 55437-1458 USA \\ ${ }^{8}$ U.S. Fish and Wildlife Service, La Crosse, Wisconsin 54603 USA \\ ${ }^{9}$ University of Victoria, Centre for Biomedical Research, Victoria, British Columbia V8P 5C2 Canada \\ ${ }^{10}$ Stockholm Resilience Centre, Stockholm University, SE-10691, Stockholm, Sweden \\ ${ }^{11}$ National Oceanographic and Atmospheric Administration Great Lakes Environmental Research Laboratory, \\ Ann Arbor, Michigan 48108 USA \\ ${ }^{12}$ School of Natural Resources, University of Nebraska, Lincoln, Nebraska 68583 USA
}

\begin{abstract}
Ecological structures and processes occur at specific spatiotemporal scales, and interactions that occur across multiple scales mediate scale-specific (e.g., individual, community, local, or regional) responses to disturbance. Despite the importance of scale, explicitly incorporating a multi-scale perspective into research and management actions remains a challenge. The discontinuity hypothesis provides a fertile avenue for addressing this problem by linking measureable proxies to inherent scales of structure within ecosystems. Here we outline the conceptual framework underlying discontinuities and review the evidence supporting the discontinuity hypothesis in ecological systems. Next we explore the utility of this approach for understanding cross-scale patterns and the organization of ecosystems by describing recent advances for examining nonlinear responses to disturbance and phenomena such as extinctions, invasions, and resilience. To stimulate new research, we present methods for performing discontinuity analysis, detail outstanding knowledge gaps, and discuss potential approaches for addressing these gaps.
\end{abstract}

Key words: body mass; competition; discontinuity hypothesis; extinction; function; hierarchy theory; invasion; multiple-scale analysis; nonlinear responses; regime shift; resilience.

\section{INTRODUCTION}

Toward the end of the 20th century, ecology underwent a conceptual shift from a linear, continuous view of ecosystem processes and structures to one that emphasized nonlinearity and the discontinuous nature of many variables and processes (Wiens 1989, Solé and Bascompte 2006). Ecosystems are strongly influenced by

Manuscript received 9 July 2013; revised 23 August 2013; accepted 26 August 2013. Corresponding Editor: H. Hillebrand.

${ }^{13}$ E-mail: nashkirsty@gmail.com biotic and abiotic processes that operate over different spatial and temporal scales (Levin 1992, Peterson et al. 1998, Peters et al. 2007). Therefore, although small-scale observations provide an important route to explore ecosystem dynamics, it is critical to understand how patterns and processes observed at finer scales represent those operating over broader spatiotemporal scales, and similarly, how large-scale processes correspond to smallscale phenomena (Levin 1992, Cooper et al. 1998, Scheffer and van Nes 2007). These multi-scale patterns will affect the manner in which ecosystems respond to disturbance operating over different scales (Peters et al. 
TABLE 1. Glossary of terms.

\begin{tabular}{|c|c|}
\hline Term & Definition \\
\hline Aggregation & $\begin{array}{l}\text { Clusters of measurements in the distribution of a variable. In a body size distribution, an } \\
\text { aggregation is a cluster of species that are of similar size. Synonymous with lump or mode in } \\
\text { the distribution and driven by the underlying pattern of resource availability or habitat } \\
\text { structure, although a focus on modality differs from one on discontinuity in that the expected } \\
\text { mechanisms are different (see Discontinuous and Multi-model distribution). An aggregation is } \\
\text { separated from its neighbor by a discontinuity. }\end{array}$ \\
\hline Discontinuity & $\begin{array}{l}\text { Break in the distribution of a variable. In a body size distribution, this would be a region of the } \\
\text { distribution with no species. Synonymous with gap and driven by an underlying break } \\
\text { between "intrinsic" scales (see Appendix A for further details). Discontinuities separate } \\
\text { aggregations in the distribution. }\end{array}$ \\
\hline Discontinuous distribution & $\begin{array}{l}\text { The distribution of a variable where measurements are clustered in groups along the axis, and } \\
\text { clusters are separated from each other by gaps (cf. multi-modal distribution). For example, a } \\
\text { body mass distribution, where species of similar size are clustered in aggregations separated } \\
\text { from species of different size by gaps or discontinuities in body mass. Methods aimed at } \\
\text { evaluating distributions for discontinuities look for gaps rather than aggregations. }\end{array}$ \\
\hline Ecological resilience & $\begin{array}{l}\text { A measure of the amount of change needed to transform an ecosystem from one set of processes } \\
\text { and structures to a different set. An ecosystem with high resilience would require a substantial } \\
\text { amount of energy to transform, whereas a low-resilience system would transform with a } \\
\text { relatively small amount of energy. }\end{array}$ \\
\hline Intrinsic scales & $\begin{array}{l}\text { Sections of the scale spectrum where process-pattern relationships are consistent, i.e., they are } \\
\text { homogeneous or change monotonically, and persist over the time scale of interest (Stallins } \\
\text { 2006). Also termed scale domains (see Appendix A). A domain is separated from neighboring } \\
\text { domains by breaks, which are zones of variability where there is a change in the dominant } \\
\text { processes. }\end{array}$ \\
\hline Multi-modal distribution & $\begin{array}{l}\text { The distribution of a variable where measurements are clustered along the axis. Clusters may be } \\
\text { separated from each other by troughs in the distribution (cf. discontinuous distribution). } \\
\text { Methods aimed at evaluating modality of a distribution look for modes rather than gaps. }\end{array}$ \\
\hline Process & $\begin{array}{l}\text { In this context, process includes endogenous processes such as herbivory and exogenous drivers } \\
\text { such as a storm. These processes and drivers operate over a discrete range of spatial and } \\
\text { temporal scales, forming "intrinsic" scales within a system. }\end{array}$ \\
\hline
\end{tabular}

2007); therefore, knowledge of how pattern-process relationships are distributed across scales is crucial for a better understanding of the current state of ecosystems and to make predictions of their response to change.

Despite this interest in scale-specific patterns, effective implementation of a multi-scale approach in theoretical and empirical research remains elusive (Wheatley and Johnson 2009). This is primarily due to the difficulties of identifying appropriate scales and the logistics of targeting multiple scales during data collection (Addicott et al. 1987). Analysis of discontinuities (Table 1) found within a range of abiotic and biotic variables, such as habitat structure, body mass, and range size (e.g., Fischer et al. 2008, Gunderson 2008, Restrepo and Arango 2008), offers a fertile avenue for examining processes and interactions in a multi-scale context. This approach allows the identification of scale-specific relationships among ecosystem drivers and processes, habitat structure, resource availability, and organisms. Here, we outline and evaluate evidence for a conceptual framework that accounts for discontinuities within ecosystems and draw links to work in other ecological and biological fields such as hierarchy theory. Second, we provide and describe tools for evaluating discontinuities across a range of data types. Third, we explore the emerging literature incorporating discontinuity analysis. We illustrate how this approach may be used to address a range of ecological questions regarding cross-scale patterns in abundance, function, diversity, and organismal traits as they relate to that pattern, as well as to emergent phenomena such as resilience. Finally, we highlight the potential limits of applying discontinuity theory and analyses to specific systems and the current gaps in knowledge, providing stimulus for new research.

\section{Discontinuities: Framework, Evidence, AND EXTENSIONS \\ Conceptual framework}

The discontinuity approach is derived from hierarchy theory (Appendix A). Growing evidence from nature and ecological modeling suggests that ecosystem structure and dynamics are dominated by the influence of a small set of plant, animal, and abiotic processes operating at specific temporal periodicities and spatial scales, forming a hierarchy (O'Neill et al. 1986, Holling 1992). Each level in this nested hierarchy of variables is controlled by processes sufficiently different in speed and size to introduce discontinuities in the distribution and pattern of ecosystem attributes such as habitat structure and resource availability (Fig. 1; see Allen and Starr 1982, O’Neill et al. 1986, Kolasa 1989). Thus ecological structure varies with scale and reflects the actions of the particular processes operating at a given scale. Such discontinuous hierarchical patterns of processes, structure, and resources were first proposed in systems theory over 50 years ago (Simon 1962). Some 30 years later, ecologists began applying these concepts to describe and understand a 


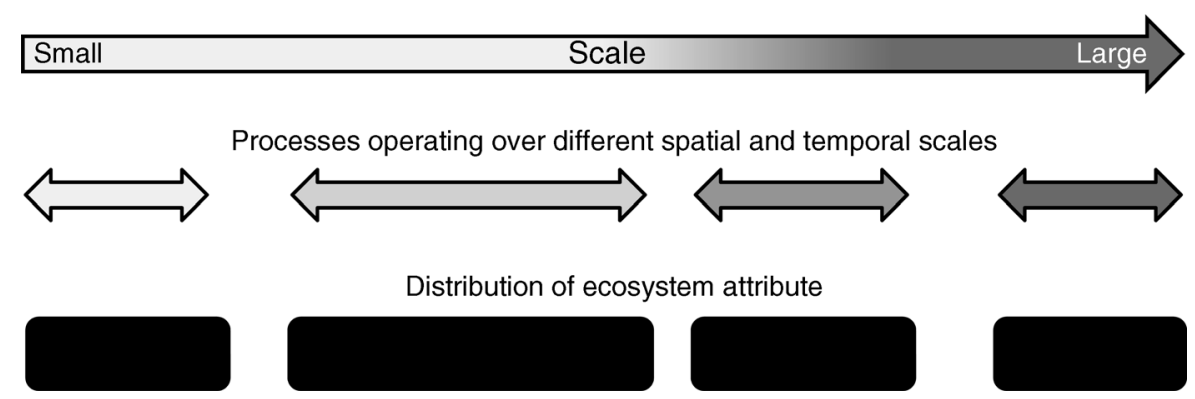

FIG. 1. Multi-scale relationship between processes occurring over different, discrete spatial and temporal scales, and the resulting discontinuous distribution of an ecosystem attribute, such as physical habitat structure. The distribution of processes over discrete scale ranges, and the landscape patterns they produce, represent the "intrinsic" scales (Table 1) of a system (adapted from Wiens 1989). Discontinuities, or zones of low or variable resource availability, lie between these "intrinsic" scales.

range of aquatic and terrestrial ecosystems (Levin 1992, Gillson 2004, Gunderson 2008). For example, the scales of food and shelter afforded by the physical structures of a coral reef ecosystem vary from individual coral branches up to multi-reef complexes, with implications for the abundance of associated organisms (Fig. 2a; see Nash et al. 2013). Discontinuous, hierarchical structure is being used to assess hydro-geomorphic processes in fluvial systems (Poole 2002), and the concept underpins considerable work in landscape ecology (e.g., Kolasa 1989, Pavlacky and Anderson 2007, Johnson 2009).

A number of theoretical frameworks have linked patterns in habitat structure to attributes of associated communities (e.g., MacArthur and Wilson 1967, Milne et al. 1992, Brown 1995, Ritchie 1998). The discontinuity hypothesis, as originally framed by Holling (1992), proposed that where ecosystem patterns are persistent over ecological time scales, biological processes unrelated to the original structuring processes will become entrained by and adapted to the pattern across scales. For example, life history, behavioral, and morphological attributes of animals may adapt to the discontinuous landscape pattern as this pattern reflects opportunities for shelter, food, and resources (Fauchald and Tveraa 2006). However, these opportunities are mediated by the scales at which individuals interact with the landscape and exploit resources (Holling 1992, Haskell et al. 2002), and the scales of these interactions are positively correlated with body size (Peters 1983).

Holling (1992) found a correlation between breaks in distributions of animal body masses and discontinuities in structures and processes in the boreal forest of Canada. At about the same time, similar hypotheses were presented in paleontology (Legendre 1986, Travouillon and Legendre 2009). Aggregations of species (or modes; Table 1) along body mass distributions indicate scales at which resources and structure are available to organisms and persist within a given landscape over ecological time scales (Fig. 2). In contrast, gaps (discontinuities or troughs) in the distribution reflect the transition to a new set of structuring processes, and therefore few and highly variable resources (Wardwell and Allen 2009). Because animals themselves often strongly modify their environment, such interactions facilitate and reinforce the resources and structure at specific scales (e.g., Bozec et al. 2012).

\section{Modeling and empirical evidence}

Discontinuous and multi-modal body size distributions (Table 1) have been observed in numerous ecological systems, including both terrestrial and aquatic ecosystems. Studied taxa include birds (Fischer et al. 2008, Skillen and Maurer 2008, Thibault et al. 2011), reptiles and amphibians (Allen et al. 1999), fish and plankton (Havlicek and Carpenter 2001), and mammals (Lambert 2006, Rodríguez et al. 2008, Wardwell et al. 2008). Separate work looking at other species and community attributes, such as species' abundances and biomass (Angeler et al. 2011), richness (Warwick et al. 2006), range size (Restrepo and Arango 2008), and occupancy patterns (Hartley et al. 2004) across spatial and temporal scales, show similar discontinuous distributions (Table 1).

Similarities in body size distributions among different taxa within a single ecosystem (that are thus exposed to the same habitat structure), and body size distributions of a single taxa among structurally similar systems, have been presented as evidence of the influence of habitat on body size distributions (Holling 1992, Sendzimir 1998). However, the specific mechanisms driving the link between body size and hierarchical habitat structure need explicit exploration (Robson et al. 2005). Szabó and Meszéna (2006) modeled competitive interactions among species of different sizes and showed that the positive relationship between body size and the scale at which species perceive and use resources (Peters 1983, Laca et al. 2010) will produce discontinuous body size distributions where resources are heterogeneously distributed across scales. Empirical studies exploring the link between habitat structure and body size distributions provide further indications of the importance of scaling of the perception of resources with body size. 
a

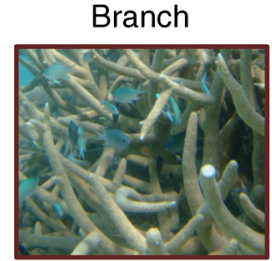

$\uparrow$

Aggregation 1

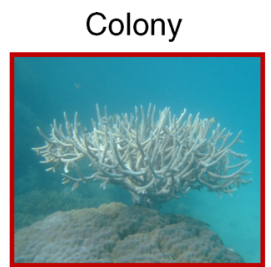

$\uparrow$

Aggregation 2
Multi-colony

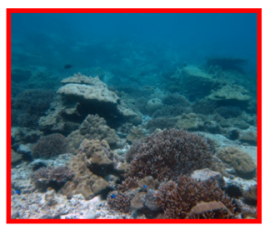

$\downarrow$

Aggregation 3
Reef

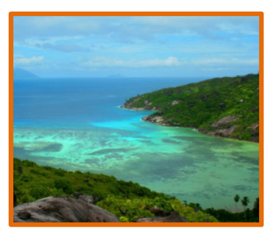

$\uparrow$

Aggregation 4
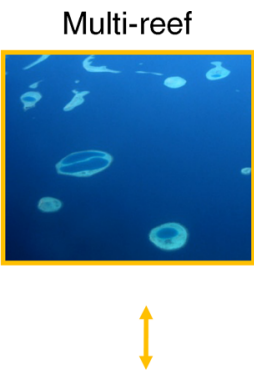

Aggregation 5
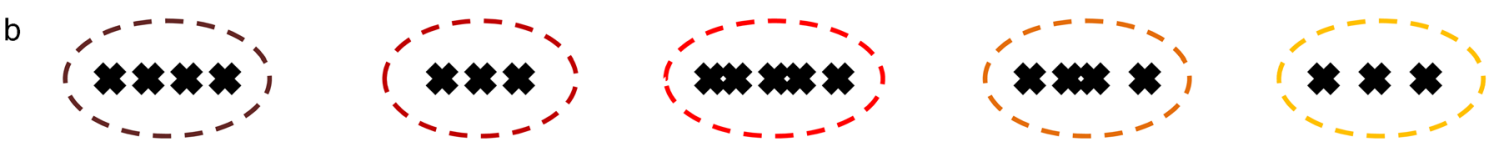

$\log ($ body size)

\section{Scale of perception}

C

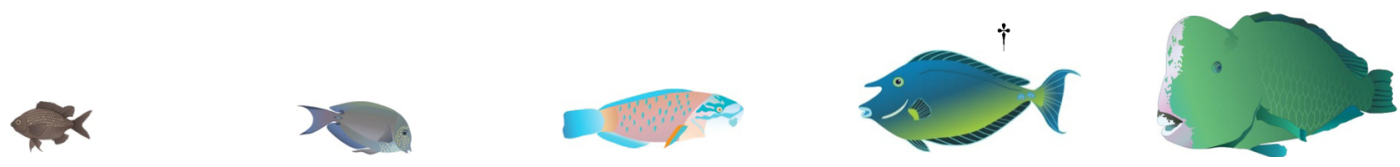

FIG. 2. Relationship between scales of habitat structure and discontinuities in body size distributions. (a) Discontinuous hierarchy of scale for structure and resources within a reef ecosystem, from the individual branches of coral colonies to multi-reef scales. (b) A discontinuous fish body size distribution. Crosses represent individual species; aggregations (dashed circles) of similarly sized species operate at similar scales, and are separated from neighboring aggregations by discontinuities. Body size correlates with scale of perception, such that larger species operate over larger scales. (c) Representative species from each of the five aggregations. For example, the blue spine unicornfish (with dagger symbol) is a member of aggregation 4, and perceives and interacts with its habitat at the reef scale. The multi-reef image is courtesy of James Oliver (http://www.reefbase.org); fish vector graphics are courtesy of, from right to left, Tracey Saxby, Joanna Woerner, Joanna Woerner, Christine Thurber, and Tracey Saxby (Integration and Application Network, http://ian.umces.edu/imagelibrary/).

For example, the distributions of food and habitat resources at different spatial and temporal scales have been shown to influence body size distributions in deserts (Borthagaray et al. 2012), forests (Fisher et al. 2011), and transition zones between rain forest and savannah habitats (Smith et al. 1997), and availability of shelter to different-sized fish has been linked to body depth distributions in reef ecosystems (Nash et al. 2013). Similarly, thinning of tree stands, reducing the fine-scale complexity of forest habitats, influences bird body size distributions, resulting in smaller mean body size (de la Montaña et al. 2006). In contrast, research investigating the influence of habitat structure on invertebrate body size distributions has produced mixed results (Gunnarsson 1992). Marine intertidal communities show evidence of distributions driven by sediment structure (Schwinghamer 1981), whereas seasonal and spatial changes in body size distributions are significant in freshwater sediment infaunal communities, suggesting that habitat structure is less important in this context (Stead et al. 2005).
The discontinuity hypothesis represents one of a number of proposed drivers of body size distributions (e.g., Brown et al. 1993, Hubbell 2001, Scheffer and van Nes 2006). However, these drivers are, by and large, complementary as they reflect multiple mechanisms operating at distinct scales. Hypotheses such as community interaction, biogeographical, phylogenetic, and discontinuity hypotheses explain pattern and allometry at distinctly different spatial and temporal scales (reviewed in Allen et al. 2006). The phylogenetic hypothesis, for example, is appropriate at continental scales (Cassey and Blackburn 2004), whereas the discontinuity hypothesis is relevant at regional scales (Allen et al. 2006).

There has been some debate regarding the relative importance of the discontinuity hypothesis vs. emergent neutrality in driving discontinuous distributions at similar scales. The latter hypothesis proposes that competitive interactions alone can generate a discontinuous body mass distribution, although the locations of the modes are the result of stochasticity and so differ from community to community (Scheffer and van Nes 
2006). This is in contrast to the discontinuity hypothesis, which proposes that the location of modes is driven by biota interacting with habitat structure, and therefore would be similar among sites characterized by the same habitat. Thibault et al. (2011) examined biomass size spectra of breeding and overwintering birds at multiple scales and found strong consistency in the number and location of the modes, suggesting non-stochastic structuring processes at work. In contrast, Vergnon et al. (2012) found evidence supporting emergent neutrality in plankton communities, although their treatment of migrants may not be applicable to terrestrial systems, and their representation of the discontinuity hypothesis should be modified; the discontinuity hypothesis predicts weaker interactions among species operating at different scales compared with those operating at similar scales (Fig. 3); this is contrary to the idea of no interaction as suggested by Vergnon et al. (2012). These contrasting results may be a function of the relative complexity of the different ecosystems under study. More work is needed to understand the mechanisms responsible for body size distributions at defined scales and in a wider range of ecosystems to assess scale- and system-specific factors that may influence this relationship (Sendzimir et al. 2003, Robson et al. 2005, YvonDurocher et al. 2011).

\section{Extensions to original framework}

Coincident with the growing body of evidence for discontinuities in numerous ecological systems, a number of species' attributes have been shown to be associated with discontinuous body mass patterns. These include invasion, extinction, high population variability, migration, and nomadism (Allen et al. 1999, Allen and Holling 2002, Wardwell and Allen 2009). Additionally, the roles that species play and the distribution of the functional attributes of these species within and across scales may strengthen the resilience of ecological systems (Peterson et al. 1998, Walker et al. 1999). Peterson et al. (1998) expanded upon Holling's (1992) discontinuity hypothesis by proposing that functional diversity within body mass aggregations and redundancy of functional groups across body mass aggregations (i.e., scales) support system resilience (see Applications section). Despite these advances, much of the potential of evaluating discontinuities and their implications for addressing a broad range of ecological questions remains unexplored.

\section{Applications of Discontinuity Analysis}

Evaluating and analyzing data for discontinuous patterns (Table 2) has two primary uses. First, it is an independent method for identifying "intrinsic" scales (Table 1, Fig. 1) of pattern and process in ecosystems. Second, it provides a platform from which to assess the distribution of key traits or processes within and across the scales of any given system. As a result, it may be used to explain cross-scale patterns such as abundance, functionality, diversity, and organismal traits as they relate to that pattern, as well as emergent phenomena such as resilience.

\section{Identification of scales}

Incorporating a multi-scaled perspective into empirical research remains a key issue, with choice of discrete scales often being arbitrary (Levin 1992, Wheatley and Johnson 2009). Such subjectivity introduces two problems. First, the scales chosen may be relevant for a subset of focal species or ecological processes, but may not be suitable for all species or processes of interest (Davidson et al. 2012). Second, the relevance of theoretical models to empirical results may be masked due to a scale mismatch (Addicott et al. 1987, Roubicek et al. 2010), with the inherent danger that findings are an artifact of ad hoc scale choices and effects (Wiens 1989, McGeoch and Gaston 2002, Halley et al. 2004, Lechner et al. 2012).

Selecting scales for investigation and analysis that are relevant to the particular individual, population, or community is, therefore, a goal of effective ecological research. This has resulted in the development of a range of multi-scale methods for identifying "intrinsic" scales in ecosystems, largely arising out of work on hierarchy theory in landscape ecology ( $\mathrm{Wu}$ and $\mathrm{Li}$ 2006). However, the information needed to make such informed decisions is often considerable (Addicott et al. 1987). Discontinuity analysis provides a method for detecting underlying scales of process and structure in a system, which is not dependent on arbitrary methodological choices and is relatively data inexpensive, using simple proxies such as animal body size (Appendix B; Holling 1992, Wardwell and Allen 2009) or how patterns change across scales (Bradbury et al. 1984, Hartley et al. 2004).

Such analyses present a number of important opportunities, including the ability to: (1) differentiate between systems exhibiting scale invariance of variables and processes (i.e., consistent patterns across scales) vs. those with discrete, "intrinsic" scales (see "power laws" and "scale domains" in Appendix B; Wiens 1989, Kerkhoff and Enquist 2007); (2) reduce the arbitrariness of scale selection and increase the likelihood of designing effective multi-scale studies (Wheatley and Johnson 2009); (3) delimit the appropriate scales for ecological surrogates (Hartley et al. 2004, Januchowski-Hartley et al. 2011); (4) predict congruence in the response of species to disturbance or environmental drivers (Peterson et al. 1998, Chen et al. 2011); and (5) partition out variance associated with scale effects prior to running other analyses. An example of such an analytical integration is seen in tests for priority effects in Hawaiian avifauna (C. R. Allen, M. P. Moulton, and C. S. Holling, unpublished data). Inhibitory priority effects describe the negative influence of species already present at a site on the colonizing ability of new species (Belyea and Lancaster 

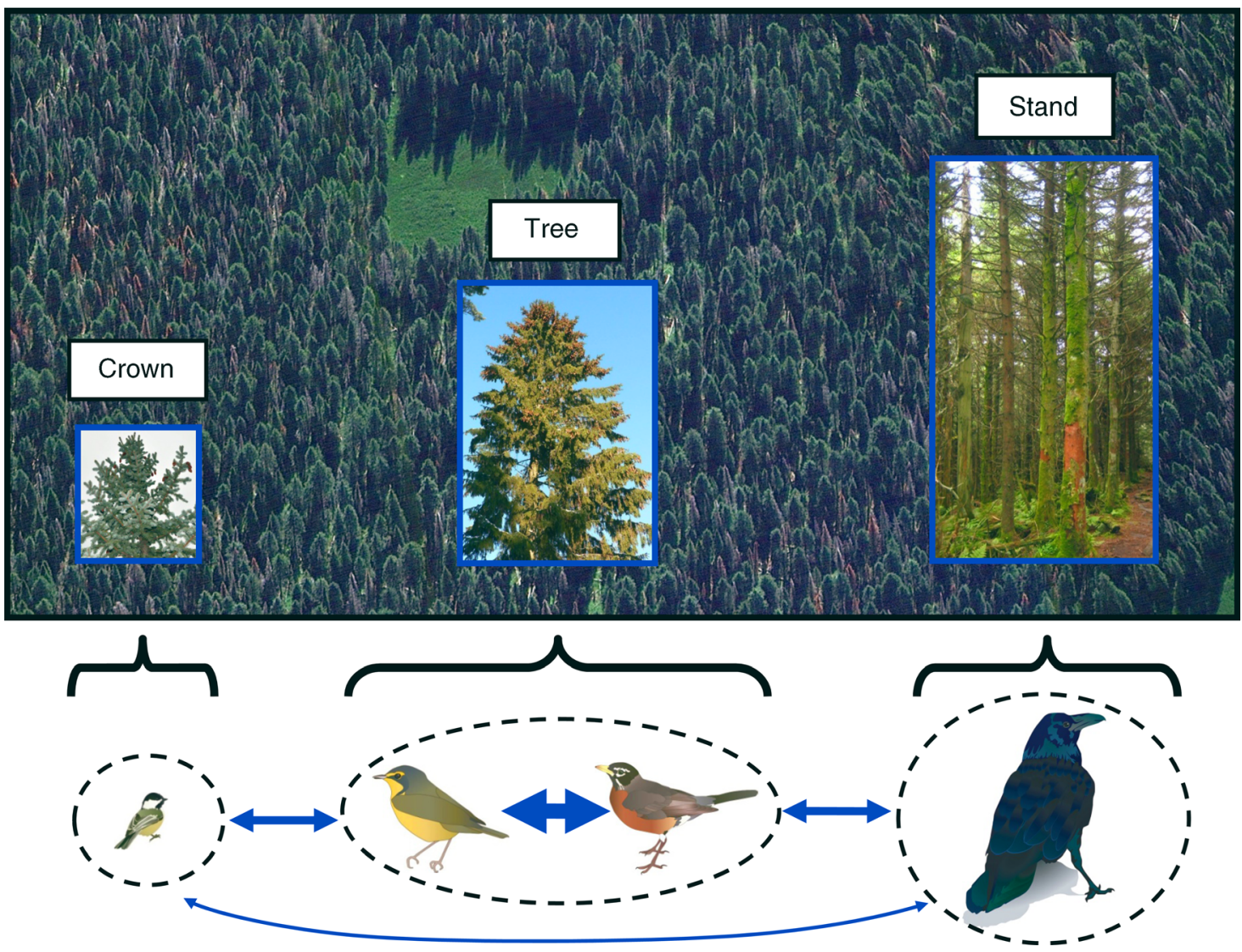

FIG. 3. Strength of competitive interactions among species using similar resources at different scales. The range of scales at which birds in different body size aggregations perceive and feed on spruce budworm extends from the crown of a fir to a stand of trees, and these sit within larger spatial scales (forest). Blue arrows represent the relative strength of competitive interactions among these species. When species are located within the same body size aggregation (dashed circles), they forage over similar scales and thus experience relatively strong competitive interactions (thick arrow) compared with species in different body size aggregations that are foraging at different scales (thinner arrows). The tree aerial photo is courtesy of Google Earth; the spruce tree image is courtesy of Rosendahl (http://www.public-domain-image.com/); chickadee, warbler, and robin graphics are courtesy of Tracey Saxby (Integration and Application Network, http://ian.umces.edu/imagelibrary/); the crow image is (C)an Stock Photo/ Birchside).

1999). The strength of the negative relationship between the number of species present in the Hawaiian bird community and the success of introduced species was strengthened when body size was accounted for, i.e., membership within a specific body size aggregation was used as a blocking factor in the analysis of variance. This outcome is linked to scale-specific competitive interactions; species within the same aggregation are predicted to experience greater interspecific competition than with species in other aggregations (Fig. 3; see Peterson et al. 1998). As a result, priority effects are stronger in aggregations containing greater numbers of species (C. R. Allen, M. P. Moulton, and C. S. Holling, unpublished data).

Evaluations of discontinuities in body size distributions are based on links between body size and patterns of habitat structure, driven by the scale at which species interact with their environment (Szabó and
Meszéna 2006, Fisher et al. 2011, Nash et al. 2013). The drivers of discontinuities in other traits or community characteristics, such as biomass, are less clear and need further exploration. Nevertheless, such investigations present the opportunity to identify the "intrinsic" scales within a system and to develop clear testable hypotheses regarding mechanisms driving these hierarchies.

\section{Identification of nonlinearities and regime shifts}

Interactions among processes operating at different temporal and spatial scales can generate nonlinear behavior (Burkett et al. 2005, Peters et al. 2007). To model these dynamics and minimize "ecological surprises" at local and system-wide scales, development of robust methods for detecting and evaluating nonlinearities is essential (Peters et al. 2004). Discontinuity analysis may be used to explicitly identify nonlinear 
TABLE 2. Practical tools for detecting discontinuities.

\begin{tabular}{|c|c|c|c|c|c|}
\hline Method & $\begin{array}{l}\text { Discontinuities } \\
\text { or multi-modality }\end{array}$ & Data & Platform & Description & $\begin{array}{l}\text { Example } \\
\text { references }\end{array}$ \\
\hline $\begin{array}{l}\text { Bayesian } \\
\text { classification and } \\
\text { regression trees } \\
(\text { BCART) }\end{array}$ & discontinuities & mean values $\dagger$ & $\begin{array}{l}\text { executable file: } \\
\text { http://www. } \\
\text { rob-mcculloch. } \\
\text { org/code/CART/ } \\
\text { index.html }\end{array}$ & $\begin{array}{l}\text { identifies groups using } \\
\text { successive partitions of } \\
\text { the data }\end{array}$ & $\begin{array}{l}\text { Chipman et al. } \\
\text { (1998), Stow } \\
\text { et al. (2007) }\end{array}$ \\
\hline $\begin{array}{l}\text { Gap rarity index } \\
\text { (GRI) }\end{array}$ & discontinuities & mean values $\dagger$ & $\begin{array}{l}\text { BASIC; R code } \\
\text { currently under } \\
\text { development }\end{array}$ & $\begin{array}{l}\text { observed distributions are } \\
\text { compared with } \\
\text { continuous null } \\
\text { distribution and } \\
\text { significant gaps are } \\
\text { identified }\end{array}$ & $\begin{array}{l}\text { Restrepo et al. } \\
\text { (1997), Allen } \\
\text { (2006) }\end{array}$ \\
\hline $\begin{array}{l}\text { Hierarchical cluster } \\
\text { analysis }\end{array}$ & discontinuities & mean values $\dagger$ & $\begin{array}{l}\mathrm{R} \text { : hclust in stats } \\
\text { library }\end{array}$ & $\begin{array}{l}\text { identifies groups using } \\
\text { successive partitions of } \\
\text { the data }\end{array}$ & $\begin{array}{l}\text { Fischer et al. } \\
\quad(2007)\end{array}$ \\
\hline $\begin{array}{l}\text { Multivariate time } \\
\text { series modeling }\end{array}$ & discontinuities & $\begin{array}{l}\text { species } \\
\quad \text { abundance }\end{array}$ & $\begin{array}{l}\text { R: quickPCNM in } \\
\text { PCNM library }\end{array}$ & $\begin{array}{l}\text { identifies groups of species } \\
\text { exhibiting different } \\
\text { temporal trends }\end{array}$ & $\begin{array}{l}\text { Angeler et al. } \\
(2009,2012)\end{array}$ \\
\hline Fractal analysis & discontinuities & various & various & $\begin{array}{l}\text { identifies groups based on } \\
\text { changes in fractal } \\
\text { dimension across scales }\end{array}$ & $\begin{array}{l}\text { Krummel et al. } \\
\text { (1987), Nash } \\
\text { et al. (2013) }\end{array}$ \\
\hline $\begin{array}{l}\text { Kernel-density } \\
\text { estimation }\end{array}$ & modality & mean values $\dagger, \ddagger$ & $\begin{array}{l}\text { R: density within } \\
\text { stats library }\end{array}$ & $\begin{array}{l}\text { estimates probability } \\
\text { density function of a } \\
\text { variable }\end{array}$ & $\begin{array}{l}\text { Havlicek and } \\
\text { Carpenter } \\
\text { (2001) }\end{array}$ \\
\hline Mixture models & modality & mean values $\dagger, \S$ & R: OpenBUGS & $\begin{array}{l}\text { uses MCMC estimation to } \\
\text { model modality }\end{array}$ & $\begin{array}{l}\text { Xu et al. (2010), } \\
\text { Wang et al. } \\
(2012 b)\end{array}$ \\
\hline
\end{tabular}

Notes: Several methods have been described for identifying discontinuities and multi-modality within the distributions of variables such as body size or biomass. The suitability of these methods varies with respect to the type of data available and the research question (e.g., identifying discontinuities or multi-modality). All techniques have their biases (reviewed in Stow et al. 2007); therefore a combination of methods, followed by triangulation of their respective results, has been identified as the most robust approach (Stow et al. 2007). To date, mean body mass has been primarily used as a measure of body size, although for species with indeterminate growth, other metrics may be more appropriate (Robson et al. 2005). The list of platforms specified is not exhaustive.

$\dagger$ Other descriptive statistics, such as mode, median, or maximum value may be used, depending on the research question and data.

\$ May incorporate a measure of dispersion.

$\S$ May be modified to incorporate abundance.

patterns within social and ecological systems. For example, these methods have highlighted nonlinearities in both city size and plankton biomass distributions (Garmestani et al. 2007, Angeler et al. 2012). This approach can be extended to characterize nonlinear temporal behavior at the system level, to detect impending regime shifts (Allen et al. 2014).

The capacity for leading indicators, such as recovery rate, rising variance, skewness, or "flickering," to reveal approaching regime shifts has generated considerable interest (e.g., Scheffer et al. 2009, Wang et al. 2012a). Nonetheless, there is concern that proposed metrics may provide an inadequate warning period to allow policy changes in time to address and counteract forecasted shifts (Biggs et al. 2009). Discontinuity analysis may contribute to regime shift detection using existing indicators, by highlighting more sensitive variables that will provide earlier warning signals. For example, rising variance has been presented as a prospective leading indicator (Carpenter and Brock 2006). However, some populations, communities, and abiotic variables are likely to show greater variability than others; thus a method of selecting appropriate variables is needed to inform the design of monitoring programs developed to highlight ecosystem changes (Carpenter and Brock 2006, Wardwell and Allen 2009). Wardwell and Allen (2009) found rising variance in bird population abundance close to discontinuities in body mass distributions (Fig. 4), and proposed that this type of analysis could be used to highlight which variables are likely to show increased variance prior to a regime shift (Wardwell and Allen 2009).

T. L. Spanbauer et al. (unpublished manuscript) present a novel regime shift indicator based on analysis of discontinuities in species abundances over time. Multivariate time series analysis (Angeler et al. 2011) was used to successfully delimit regime shifts in lakes using paleo-diatom data. Where large spatial and temporal data sets are not available (Biggs et al. 2009), other indicators based on discontinuity analysis that require comparatively little data are proposed. The cross-scale pattern of habitat structure and body size distributions is driven by dominant processes and drivers operating over specific spatial and temporal scales (Holling 1992). Therefore, changes in the number or location of discontinuities within habitat or body size 

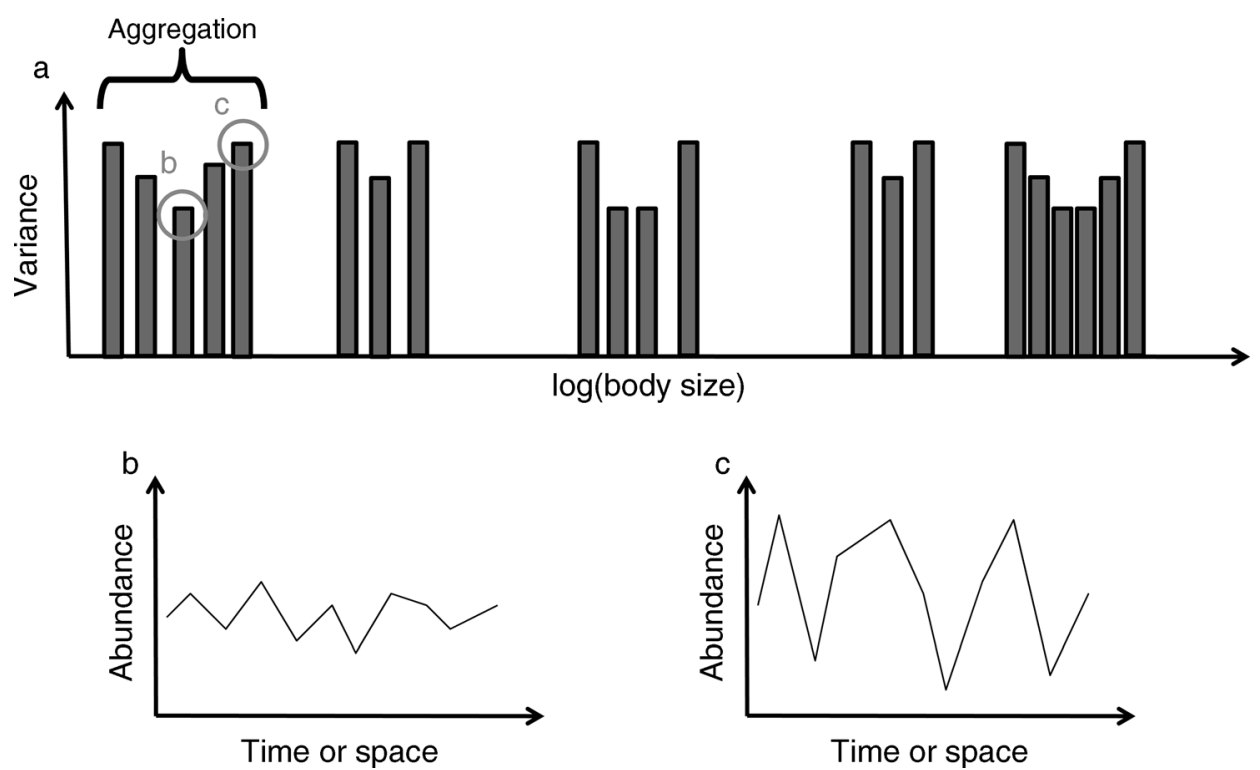

FIG. 4. (a) Patterns of variance in abundance of species located in body mass aggregations. Those species at the center of aggregations exhibit lower variance in abundance (b), than those at the edges of aggregations (c). Here body size and abundance are used as an example. Other variables may show similar patterns of aggregation and variability.

distributions over time would indicate changes in the dominant processes driving these discontinuous patterns; i.e., would provide evidence of a regime shift (Holling 2001). Such changes have been observed spatially in bird communities, among sites experiencing differing levels of landscape modification (Fischer et al. 2007). Temporal changes in the structure of body size distributions could be used to forewarn of reorganization within a system leading to a new regime. In light of research highlighting the need for robust multi-metric early warning frameworks (Lindegren et al. 2012), discontinuities present an innovative method with which existing metrics can be compared and combined.

\section{Functional distributions, macroecology, and resilience}

Species may be grouped according to the functional role that they play in the environment. Functions performed by vertebrate and invertebrate species include pollination, grazing, nitrogen fixation, seed dispersal, decomposition, soil nutrient generation, modification of water flows, opening up patches, and modifying environmental gradients within the landscape (Folke et al. 2004). Body size is a proxy for the scale at which species operate (Peters 1983); therefore, body size distributions can be combined with functional classifications to describe and enumerate the distribution of members of functional groups within and across scales, i.e., the range of scales over which each group delivers its functional role. This information is of direct interest to two fields of ecology: macroecology and resilience (Kerkhoff and Enquist 2007).

There has been an increasing recognition that competitive and other forms of intra- and interspecific interactions need to be incorporated into macroecolog- ical studies (Araújo and Luoto 2007), but to date there has been a lack of clarity regarding the influence of competition on local assembly (Gotelli et al. 2010). Where studies have incorporated competition, the strength of interactions has been inferred from membership within species or functional groups (e.g., Gotelli et al. 2010). Peterson et al. (1998) predict that species using similar resources could minimize competitive interactions via differentiation of the scales at which they operate (Fig. 3). Therefore, members of a functional group are more likely to be distributed across scales (and thus body size aggregations) than expected by chance. This nonrandom pattern has been demonstrated in bird and mammal populations (Wardwell et al. 2008), suggesting that functionally similar species within the same body size aggregation are subject to stronger interactions than those operating at different scales (Peterson et al. 1998). As a result, macroecological studies that group species according to body size aggregation would provide a clearer picture of the likely strength of competitive interactions among species using similar resources, and may help to resolve some of the current uncertainties. The effectiveness of this approach was illustrated in the discussion on Hawaiian avifauna priority effects.

Redundancy of species within functional groups is thought to underpin ecological resilience, as it reflects the potential for each group to compensate for the loss of one or multiple species in the face of disturbance, and thus continue to drive ecological processes (Fig. 5a, b; see Walker et al. 1999, Sundstrom et al. 2012). But the value of this redundancy is misleading if each species responds to a disturbance in a similar manner. Species interacting with their environment at different scales are 
likely to respond to disturbances differently (Fig. 5b, c; see Elmqvist et al. 2003); therefore, the scale-specific distribution of functions may be used to quantify the degree of cross- and within-scale redundancy of an assemblage (Allen et al. 2005). This approach, known as the cross-scale resilience model, has been tested on bird community data from southeastern Australia, providing promising results that indicate reduced resilience of modified landscapes (Fischer et al. 2007). However, there is a need to evaluate these metrics in a wider range of ecosystems and taxa. Furthermore, opportunities remain to examine the effects of abundance on functional redundancy (Walker et al. 1999) and to incorporate trait-based functional categorization that transcends the relatively coarse nature of some functional classifications (Fischer et al. 2007).

The distribution of functional groups in time and space may indicate the scales at which species are fulfilling their role. However, the relative impact of organisms of different body sizes is inextricably linked to individual abundance (White et al. 2007). Therefore decline in the abundance of common species, which may form habitat structure within an ecosystem and/or drive key processes (Gaston and Fuller 2008), has significant implications for functional impact at different spatial and temporal scales, which is not quantified by functional distributions alone. The role of species abundance in resilience is largely unexplored, except in the general sense that minor species can sometimes be functional substitutes for more dominant species whose populations are depressed after a disturbance (Walker et al. 1999). To date, the cross-scale resilience model and empirical evaluations of this model have not incorporated abundance and its influence on the functions that species perform (Peterson et al. 1998, Fischer et al. 2007). There is a clear need to address this gap through the addition of abundance into current models relating biological diversity to resilience.

A more detailed characterization of species roles, other than simple functional groups, is possible through the use of multidimensional functional space indices. This approach has been used to examine drivers of community assembly (Ackerly and Cornwell 2007), the delivery of ecosystem processes (Pakeman 2011), and has been proposed as a way of predicting the response of communities to specific disturbances (Mouillot et al. 2012). Mouillot et al. (2012) discuss body size as one of a number of possible traits that may vary in response to disturbance. Therefore, classifying species according to body mass aggregation in a functional trait-based analysis would explicitly group species operating at similar scales and thus incorporate scale-specific response to disturbance, increasing the sensitivity of such analyses.

The resilience of an ecosystem to specific disturbances may be related to connectivity among habitat patches. This connectivity may be passive (e.g., propagules) or due to mobile links, i.e., individuals moving between areas (Nyström and Folke 2001). Characterizing distributions of function across scales will highlight the likely spatial extent of mobile links and identify vulnerabilities due to a narrowing of the range of scales over which an assemblage is functionally effective (Nyström 2006). For example, large reef fish are subject to extreme fishing pressure in certain areas, resulting in the removal of those species that operate over large scales and thus provide critical linkages among locations across the broader seascape (Jackson et al. 2001, McCauley et al. 2012). This loss has significant implications for the connectivity and spatial resilience of coral reefs, and limits the likelihood of mobile links connecting undamaged reefs with those impacted by disturbance (Fig. 5).

\section{Extinctions and invasions}

The rising number of invasions by nonindigenous species and extinctions in terrestrial and aquatic environments are of serious concern (Pimentel et al. 2005, Vié et al. 2009). These changes are often associated with significant modifications to habitats and food webs, with important ramifications for the delivery of ecosystem services and the maintenance of key ecosystem processes (Simberloff et al. 2013). For example, in New Zealand, functional extinction of some bird species has significantly reduced pollination of endemic plant species, leading to reduced plant density (Anderson et al. 2011). The cost associated with the impact of invasive species in the United States alone is estimated to exceed US\$100 billion per annum (Pimentel et al. 2005).

Predicting the likelihood of a species either becoming extinct or being introduced and then successfully establishing a breeding population, is critical for management and for mitigation efforts. However, such prediction is extremely difficult due to the range of species-, community-, and habitat-level factors influencing the decline of species and the success of invasions (Brook et al. 2008, Hayes and Barry 2008, Harnik et al. 2012). Nonetheless, proximity to the edge of body mass aggregations has been found to be a significant predictor of invasion success for both bird and mammal species, and of extinction risk among mammals (Allen et al. 1999, Allen 2006). Edges of body mass aggregations are associated with increased variability in abundance (Wardwell and Allen 2009), and are linked to less predictable resource availability (Fig. 4; see Wiens 1989). Consequently, these edges represent locations where species may be more susceptible to extinction or more able to exploit opportunities (Allen et al. 1999, Allen 2006). The strength of using proximity to a discontinuity in the body mass distribution as a predictor is that it incorporates both community- and habitat-level factors. Specifically it indicates the likely level of competition experienced by an invading species (Fig. 3) and the scales at which resources are available to species, because body mass distributions are thought to reflect underlying habitat structure. In ecosystems where body size aggregations are demonstrated to reflect the 
a

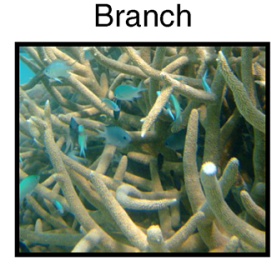

Colony

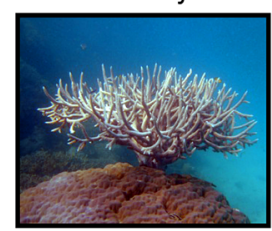

Multi-colony

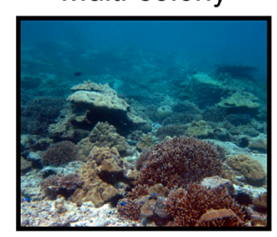

Reef

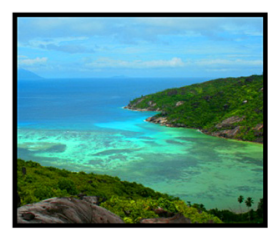

Multi-reef

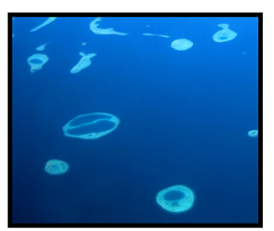

b) Pre-disturbance

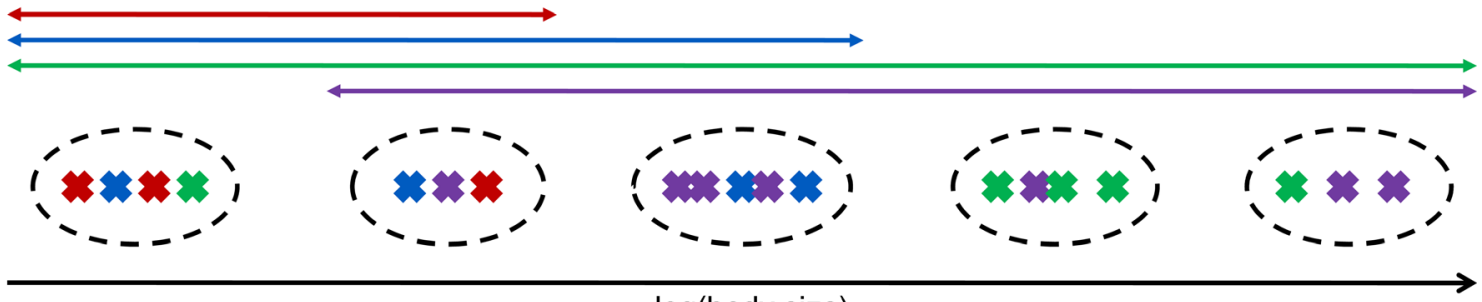

$\log ($ body size)

\section{c) Post-disturbance}

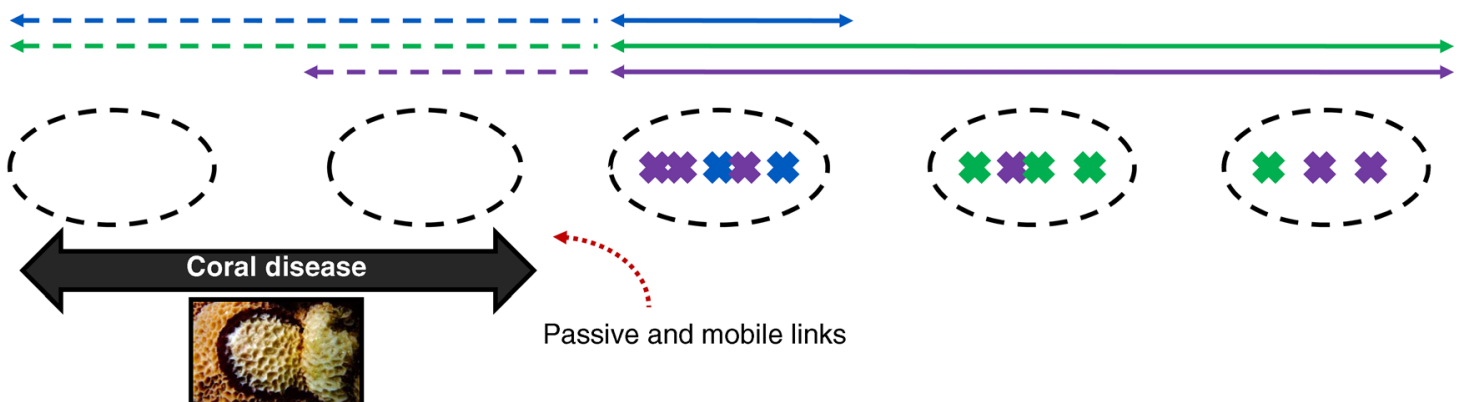

FIG. 5. Influence of disturbance on the distribution of functional groups across scales. (a) The range of scales at which fish perceive, interact with, and use resources on the reef, from the individual branches of coral colonies to multi-reef scales. (b) Predisturbance: discontinuous fish body size distribution, where crosses represent individual species and colors indicate functional group membership. Colored arrows indicate the range of scales over which each group operates and therefore provides its function: the green functional group operates over a wide range of scales, whereas the red functional group only operates over small scales. (c) Post-disturbance: coral disease provides a small-scale disturbance that affects fish species operating at the branch and colony scales (empty aggregations). Those functional groups with redundancy across spatial scales (blue, green, and purple groups) may compensate for loss of species at these small scales (dashed arrows), whereas those functional groups with low cross-scale redundancy (red group) are reliant on passive links (recruitment) or mobile links (adult fish) recolonizing from neighboring regions (red dotted arrow) for maintenance of function. The multi-reef image is courtesy of James Oliver (http://www.reefbase.org).

underlying scales of pattern-process relationships (Borthagaray et al. 2012), the distribution of extinctions and invasions across body mass distributions can also be used to identify scales particularly vulnerable to change and impact (Cardillo and Bromham 2001, Petchey and Gaston 2002, Woodward et al. 2005). In addition, proximity to discontinuities can be used to predict extinctions or the likely success of invasions of introduced species, prior to their occurrence or establishment, respectively. Considering the global threats that extinction and invasion present (for example, 56 species of amphibians and reptiles have successfully invaded and established breeding populations in Florida alone; Krysko et al. 2011), such a predictive ability is of considerable importance. There is however, a clear need to assess the relationship between discontinuities and invasions or extinctions among taxa other than birds and mammals.

\section{Future Directions}

The discontinuity hypothesis provides a conceptual framework, arising from hierarchy theory, within which to examine the organization of ecosystems. However, much of the potential of this framework is unexploited and presents a fertile arena for original research in a wide range of ecological fields. To date, discontinuity research has primarily focused on adult body size as the variable of interest. Performing such studies on plants and modular organisms with no discrete body size, or in species that experience significant ontogenetic changes and indeterminate growth such as fish, remains a challenge that invites innovative approaches. For example, work by Angeler et al. (2013) used multivariate 
time series modeling of invertebrate species abundance in subarctic lakes as a novel way to examine patterns of function and resilience at multiple scales, which did not rely on body size metrics. To broaden the utility of discontinuity analysis, similar efforts are needed to address this challenge across the range of potential applications. Furthermore, although there is an emerging literature on the mechanistic links between habitat and body size distributions, additional studies are needed to understand the mechanisms driving discontinuities in variables such as species biomass (Angeler et al. 2011), richness (Warwick et al. 2006), and occupancy (Hartley et al. 2004).

Our discussion of modeling and empirical evidence illustrates the range of studies providing support for the discontinuity hypothesis. However, to date there has been little exploration of those systems where discontinuities are less likely to be found. The discontinuity hypothesis links cross-scale habitat structure to community attributes, such as body size, over ecological time scales. In ecosystems where such structure is less consistent over time, e.g., pelagic systems with dynamic oceanographic conditions and boundaries, discontinuous signals may not be evident. Some work has looked at discontinuities in the body mass (Havlicek and Carpenter 2001), biomass (Angeler et al. 2012), and abundance (Angeler et al. 2011) distributions of lake system communities; however, little work has investigated discontinuities in marine pelagic systems (but see Vergnon et al. 2009). It therefore remains to be seen whether, in comparatively dynamic pelagic environments, discontinuities consistently arise and may be detected.

Discontinuity analysis offers a powerful tool for investigating cross-scale interactions, as it identifies scale-specific relationships between ecosystem drivers and processes, habitat structure, resource availability, and organisms. As a consequence, it provides a platform from which to assess the distribution of key traits or processes within and across the scales of any given ecosystem, e.g., the distribution of ecological function or invasive species. There is considerable scope to broaden the application of discontinuity analysis across ecosystems and taxa, and beyond its current focus on body size applications.

\section{ACKNOWLEDGMENTS}

This work arose from discussions at the Managing for Resilience Working Group, funded by the United States Geological Survey's John Wesley Powell Center for Analysis and Synthesis. We thank two anonymous reviewers for their helpful comments. The views expressed in this paper are those of the authors and do not necessarily represent the views or policies of the U.S. Environmental Protection Agency or the U.S. Fish and Wildlife Service. The Nebraska Cooperative Fish and Wildlife Research Unit is jointly supported by a cooperative agreement among the U.S. Geological Survey, the Nebraska Game and Parks Commission, the University of Nebraska, the U.S. Fish and Wildlife Service, and the Wildlife Management Institute. GLERL contribution number 1679.

\section{Literature Cited}

Ackerly, D. D., and W. K. Cornwell. 2007. A trait-based approach to community assembly: partitioning of species trait values into within- and among-community components. Ecology Letters 10:135-145.

Addicott, J. F., J. M. Aho, M. F. Antolin, D. K. Padilla, J. S. Richardson, and D. A. Soluk. 1987. Ecological neighborhoods: scaling environmental patterns. Oikos 49:340-346.

Allen, C. R. 2006. Predictors of introduction success in the South Florida avifauna. Biological Invasions 8:491-500.

Allen, C. R., D. G. Angeler, A. S. Garmestani, L. H. Gunderson, and C. S. Holling. 2014. Panarchy: theory and application. Ecosystems, in press. http://dx.doi.org/10.1007/ s10021-013-9744-2

Allen, C. R., E. A. Forys, and C. S. Holling. 1999. Body mass patterns predict invasions and extinctions in transforming landscapes. Ecosystems 2:114-121.

Allen, C. R., A. S. Garmestani, T. D. Havlicek, P. A. Marquet, G. D. Peterson, C. Restrepo, C. A. Stow, and B. E. Weeks. 2006. Patterns in body mass distributions: sifting among alternative hypotheses. Ecology Letters 9:630-643.

Allen, C. R., L. Gunderson, and A. R. Johnson. 2005. The use of discontinuities and functional groups to assess relative resilience in complex systems. Ecosystems 8:958-966.

Allen, C. R., and C. S. Holling. 2002. Cross-scale morphology. Pages 450-452 in A. H. El-Shaarawi and W. W. Piegorsch, editors. Encyclopedia of environmetrics. John Wiley, Chichester, UK.

Allen, T. F. H., and T. B. Starr, editors. 1982. Hierarchy: perspectives for ecological complexity. University of Chicago Press, Chicago, Illinois, USA.

Anderson, S. H., D. Kelly, J. J. Ladley, S. Molloy, and J. Terry. 2011. Cascading effects of bird functional extinction reduce pollination and plant density. Science 331:1068-1071.

Angeler, D. G., C. R. Allen, and R. K. Johnson. 2012. Insight on invasions and resilience derived from spatiotemporal discontinuities of biomass at local and regional scales. Ecology and Society 17:32.

Angeler, D. G., C. R. Allen, and R. K. Johnson. 2013. Measuring the relative resilience of subarctic lakes to global change: redundancies of functions within and across temporal scales. Journal of Applied Ecology 50:572-584.

Angeler, D. G., S. Drakare, and R. K. Johnson. 2011. Revealing the organization of complex adaptive systems through multivariate time series modeling. Ecology and Society 16:5.

Angeler, D. G., O. Viedma, and J. Moreno. 2009. Statistical performance and information content of time lag analysis and redundancy analysis in time series modeling. Ecology 90: 3245-3257.

Araújo, M. B., and M. Luoto. 2007. The importance of biotic interactions for modeling species distributions under climate change. Global Ecology and Biogeography 16:743-753.

Belyea, L. R., and J. Lancaster. 1999. Assembly rules within a contingent ecology. Oikos 86:402-416.

Biggs, R., S. R. Carpenter, and W. A. Brock. 2009. Turning back from the brink: detecting an impending regime shift in time to avert it. Proceedings of the National Academy of Sciences USA 106:826-831.

Borthagaray, A. I., M. Arim, and P. A. Marquet. 2012. Connecting landscape structure and patterns in body size distributions. Oikos 121:697-710.

Bozec, Y.-M., L. Yakob, S. Bejarano, and P. J. Mumby. 2012. Reciprocal facilitation and non-linearity maintain habitat engineering on coral reefs. Oikos 122:428-440.

Bradbury, R. H., R. E. Reichelt, and D. G. Green. 1984. Fractals in ecology: methods and interpretation. Marine Ecology Progress Series 14:295-296. 
Brook, B. W., N. S. Sodhi, and C. J. A. Bradshaw. 2008. Synergies among extinction drivers under global change. Trends in Ecology and Evolution 23:453-460.

Brown, J. H. 1995. Macroecology. University of Chicago Press, Chicago, Illinois, USA.

Brown, J. H., P. A. Marquet, and M. L. Taper. 1993. Evolution of body size: consequences of an energetic definition of fitness. American Naturalist 142:573-584.

Burkett, V. R., et al. 2005. Nonlinear dynamics in ecosystem response to climatic change: case studies and policy implications. Ecological Complexity 2:357-394.

Cardillo, M., and L. Bromham. 2001. Body size and risk of extinction in Australian mammals. Conservation Biology 15: 1435-1440.

Carpenter, S. R., and W. A. Brock. 2006. Rising variance: a leading indicator of ecological transition. Ecology Letters 9: 311-318.

Cassey, P., and T. M. Blackburn. 2004. Body size trends in a Holocene island bird assemblage. Ecography 27:59-67.

Chen, I.-C., J. K. Hill, R. Ohlemüller, D. B. Roy, and C. D. Thomas. 2011. Rapid range shifts of species associated with high levels of climate warming. Science 333:1024-1026.

Chipman, H. A., E. I. George, and R. E. McCulloch. 1998. Bayesian CART model search. Journal of the American Statistical Association 93:935-948.

Cooper, S. D., S. Diehl, K. Kratz, and O. Sarnelle. 1998. Implications of scale for patterns and processes in stream ecology. Australian Journal of Ecology 23:27-40.

Davidson, Z., M. Valeix, A. J. Loveridge, J. E. Hunt, P. J. Johnson, H. Madzikanda, and D. W. Macdonald. 2012. Environmental determinants of habitat and kill site selection in a large carnivore: scale matters. Journal of Mammalogy 93:677-685.

de la Montaña, E., J. M. Rey-Benayas, and L. M. Carrascal. 2006. Response of bird communities to silvicultural thinning of Mediterranean maquis. Journal of Applied Ecology 43: 651-659.

Elmqvist, T., C. Folke, M. Nyström, G. Peterson, J. Bengtsson, B. Walker, and J. Norberg. 2003. Response diversity, ecosystem change, and resilience. Frontiers in Ecology and the Environment 1:488-494.

Fauchald, P., and T. Tveraa. 2006. Hierarchical patch dynamics and animal movement pattern. Oecologia 149:383-395.

Fischer, J., D. Lindenmayer, S. Blomberg, R. MontagueDrake, A. Felton, and J. Stein. 2007. Functional richness and relative resilience of bird communities in regions with different land use intensities. Ecosystems 10:964-974.

Fischer, J., D. B. Lindenmayer, and R. Montague-Drake. 2008. The role of landscape texture in conservation biogeography: a case study on birds in south-eastern Australia. Diversity and Distributions 14:38-46.

Fisher, J. T., B. Anholt, and J. P. Volpe. 2011. Body mass explains characteristic scales of habitat selection in terrestrial mammals. Ecology and Evolution 1:517-528.

Folke, C., S. Carpenter, B. Walker, M. Scheffer, T. Elmqvist, L. Gunderson, and C. S. Holling. 2004. Regime shifts, resilience, and biodiversity in ecosystem management. Annual Review of Ecology, Evolution, and Systematics 35:557-581.

Garmestani, A. S., C. R. Allen, C. M. Gallagher, and J. D. Mittelstaedt. 2007. Departures from Gibrat's Law, discontinuities and city size distributions. Urban Studies 44:19972007.

Gaston, K. J., and R. A. Fuller. 2008. Commonness, population depletion and conservation biology. Trends in Ecology and Evolution 23:14-19.

Gillson, L. 2004. Evidence of hierarchical patch dynamics in an east African savanna? Landscape Ecology 19:883-894.

Gotelli, N. J., G. R. Graves, and C. Rahbek. 2010. Macroecological signals of species interactions in the Danish avifauna. Proceedings of the National Academy of Sciences USA 107:5030-5035.

Gunderson, L. H. 2008. Biophysical discontinuities in the Everglades system. Pages 83-100 in C. R. Allen and C. S. Holling, editors. Discontinuities in ecosystems and other complex systems. Columbia University Press, New York, New York, USA.

Gunnarsson, B. 1992. Fractal dimension of plants and body size distribution in spiders. Functional Ecology 6:636-641.

Halley, J. M., S. Hartley, A. S. Kallimanis, W. E. Kunin, J. J. Lennon, and S. P. Sgardelis. 2004. Uses and abuses of fractal methodology in ecology. Ecology Letters 7:254-271.

Harnik, P. G., et al. 2012. Extinctions in ancient and modern seas. Trends in Ecology and Evolution 27:608-617.

Hartley, S., W. E. Kunin, J. J. Lennon, and M. J. O. Pocock. 2004. Coherence and discontinuity in the scaling of species' distribution patterns. Proceedings of the Royal Society B 271: $81-88$.

Haskell, J. P., M. E. Ritchie, and H. Olff. 2002. Fractal geometry predicts varying body size scaling relationships for mammal and bird home ranges. Nature 418:527-530.

Havlicek, T. D., and S. R. Carpenter. 2001. Pelagic species size distributions in lakes: are they discontinuous? Limnology and Oceanography 46:1021-1033.

Hayes, K., and S. Barry. 2008. Are there any consistent predictors of invasion success? Biological Invasions 10:483506 .

Holling, C. S. 1992. Cross-scale morphology, geometry, and dynamics of ecosystems. Ecological Monographs 62:447502 .

Holling, C. S. 2001. Understanding the complexity of economic, ecological, and social systems. Ecosystems 4:390-405.

Hubbell, S. P. 2001. The unified neutral theory of biodiversity and biogeography. Princeton University Press, Princeton, New Jersey, USA.

Jackson, J. B. C., et al. 2001. Historical overfishing and the recent collapse of coastal ecosystems. Science 293:629-637.

Januchowski-Hartley, S. R., V. Hermoso, R. L. Pressey, S. Linke, J. Kool, R. G. Pearson, B. J. Pusey, and J. VanDerWal. 2011. Coarse-filter surrogates do not represent freshwater fish diversity at a regional scale in Queensland, Australia. Biological Conservation 144:2499-2511.

Johnson, C. R. 2009. Natural length scales of ecological systems: applications at community and ecosystem levels. Ecology and Society 14:7.

Kerkhoff, A. J., and B. J. Enquist. 2007. The implications of scaling approaches for understanding resilience and reorganization in ecosystems. BioScience 57:489-499.

Kolasa, J. 1989. Ecological systems in hierarchical perspective: breaks in community structure and other consequences. Ecology 70:36-47.

Krummel, J. R., R. H. Gardner, G. Sugihara, R. V. O’Neill, and P. R. Coleman. 1987. Landscape patterns in a disturbed environment. Oikos 48:321-324.

Krysko, K. L., et al. 2011. Verified non-indigenous amphibians and reptiles in Florida from 1863 through 2010: outlining the invasion process and identifying invasion pathways and stages. Zootaxa 3028:1-64.

Laca, E. A., S. Sokolow, J. R. Galli, and C. A. Cangiano. 2010. Allometry and spatial scales of foraging in mammalian herbivores. Ecology Letters 13:311-320.

Lambert, W. 2006. Functional convergence of ecosystems: evidence from body mass distributions of North American late Miocene mammal faunas. Ecosystems 9:97-118.

Lechner, A. M., W. T. Langford, S. D. Jones, S. A. Bekessy, and A. Gordon. 2012. Investigating species-environment relationships at multiple scales: differentiating between intrinsic scale and the modifiable areal unit problem. Ecological Complexity 11:91-102. 
Legendre, S. 1986. Analysis of mammalian communities from the late Eocene and Oligocene of southern France. Palaeovertebrata 16:191-212.

Levin, S. A. 1992. The problem of pattern and scale in ecology: the Robert H. MacArthur Award lecture. Ecology 73:19431967.

Lindegren, M., V. Dakos, J. P. Gröger, A. Gårdmark, G. Kornilovs, S. A. Otto, and C. Möllmann. 2012. Early detection of ecosystem regime shifts: a multiple method evaluation for management application. PLoS One 7:e38410.

MacArthur, R. H., and E. Wilson. 1967. The theory of island biogeography. Princeton University Press, Princeton, New Jersey, USA.

McCauley, D. J., H. S. Young, R. B. Dunbar, J. A. Estes, B. X. Semmens, and F. Micheli. 2012. Assessing the effects of large mobile predators on ecosystem connectivity. Ecological Applications 22:1711-1717.

McGeoch, M. A., and K. J. Gaston. 2002. Occupancy frequency distributions: patterns, artefacts and mechanisms. Biological Reviews 77:311-331.

Milne, B. T., M. G. Turner, J. A. Wiens, and A. R. Johnson. 1992. Interactions between the fractal geometry of landscapes and allometric herbivory. Theoretical Population Biology 41: 337-353.

Mouillot, D., N. A. J. Graham, S. Villéger, N. W. H. Mason, and D. R. Bellwood. 2012. A functional approach reveals community responses to disturbances. Trends in Ecology and Evolution 28:167-177.

Nash, K. L., N. A. J. Graham, S. K. Wilson, and D. R. Bellwood. 2013. Cross-scale habitat structure drives fish body size distributions on coral reefs. Ecosystems 16:478-490.

Nyström, M. 2006. Redundancy and response diversity of functional groups: implications for the resilience of coral reefs. Ambio 35:30-35.

Nyström, M., and C. Folke. 2001. Spatial resilience of coral reefs. Ecosystems 4:406-417.

O’Neill, R. V., D. L. DeAngelis, J. B. Waide, and T. F. H. Allen. 1986. A hierarchical concept of ecosystems. Princeton University Press, Princeton, New Jersey, USA.

Pakeman, R. J. 2011. Multivariate identification of plant functional response and effect traits in an agricultural landscape. Ecology 92:1353-1365.

Pavlacky, D. C., and S. H. Anderson. 2007. Does avian species richness in natural patch mosaics follow the forest fragmentation paradigm? Animal Conservation 10:57-68.

Petchey, O. L., and K. J. Gaston. 2002. Extinction and the loss of functional diversity. Proceedings of the Royal Society B 269:1721-1727.

Peters, D. P. C., B. T. Bestelmeyer, and M. G. Turner. 2007. Cross-scale interactions and changing pattern-process relationships: consequences for system dynamics. Ecosystems 10: 790-796.

Peters, D. P. C., R. A. Pielke, B. T. Bestelmeyer, C. D. Allen, S. Munson-McGee, and K. M. Havstad. 2004. Cross-scale interactions, nonlinearities, and forecasting catastrophic events. Proceedings of the National Academy of Sciences USA 101:15130-15135.

Peters, R. H. 1983. The ecological implications of body size. Cambridge University Press, Cambridge, UK.

Peterson, G. D., C. R. Allen, and C. S. Holling. 1998. Ecological resilience, biodiversity, and scale. Ecosystems 1: 6-18.

Pimentel, D., R. Zuniga, and D. Morrison. 2005. Update on the environmental and economic costs associated with alieninvasive species in the United States. Ecological Economics 52:273-288.

Poole, G. C. 2002. Fluvial landscape ecology: addressing uniqueness within the river discontinuum. Freshwater Biology 47:641-660.
Restrepo, C., and N. Arango. 2008. Discontinuities in the geographical range size of North American birds and butterflies. Pages 101-135 in C. R. Allen and C. S. Holling, editors. Discontinuities in ecosystems and other complex systems. Columbia University Press, New York, New York, USA.

Restrepo, C., L. M. Renjifo, and P. Marples. 1997. Frugivorous birds in fragmented Neotropical montane forests: Landscape pattern and body mass distribution. Pages 171-189 in W. F. Laurance and R. O. Bierregaard, Jr., editors. Tropical forest remnants: ecology, management, and conservation of fragmented landscapes. University of Chicago Press, Chicago, Illinois, USA.

Ritchie, M. 1998. Scale-dependent foraging and patch choice in fractal environments. Evolutionary Ecology 12:309-330.

Robson, B. J., L. A. Barmuta, and P. G. Fairweather. 2005. Methodological and conceptual issues in the search for a relationship between animal body-size distributions and benthic habitat architecture. Marine and Freshwater Research 56:1-11.

Rodríguez, M. Á., M. Á. Olalla-Tárraga, and B. A. Hawkins. 2008. Bergmann's rule and the geography of mammal body size in the Western Hemisphere. Global Ecology and Biogeography 17:274-283.

Roubicek, A. J., J. VanDerWal, L. J. Beaumont, A. J. Pitman, P. Wilson, and L. Hughes. 2010. Does the choice of climate baseline matter in ecological niche modeling? Ecological Modelling 221:2280-2286.

Scheffer, M., J. Bascompte, W. A. Brock, V. Brovkin, S. R. Carpenter, V. Dakos, H. Held, E. H. van Nes, M. Rietkerk, and G. Sugihara. 2009. Early-warning signals for critical transitions. Nature 461:53-59.

Scheffer, M., and E. H. van Nes. 2006. Self-organized similarity: the evolutionary emergence of groups of similar species. Proceedings of the National Academy of Sciences USA 103:6230-6235.

Scheffer, M., and E. H. van Nes. 2007. Shallow lakes theory revisited: various alternative regimes driven by climate, nutrients, depth and lake size. Hydrobiologia 584:455-466.

Schwinghamer, P. 1981. Characteristic size distributions of integral benthic communities. Canadian Journal of Fisheries and Aquatic Sciences 38:1255-1263.

Sendzimir, J. 1998. Patterns of animal size and landscape complexity: correspondence within and across scales. Dissertation. University of Florida, Gainesville, Florida, USA.

Sendzimir, J., C. R. Allen, L. H. Gunderson, and C. A. Stow. 2003. Implications of body mass patterns: linking ecological structure and process to wildlife conservation and management. Pages 125-152 in J. Bissonette and I. Storch, editors. Landscape ecology and resource management: linking theory with practice. Island Press, Washington, D.C., USA.

Simberloff, D., et al. 2013. Impacts of biological invasions: What's what and the way forward. Trends in Ecology and Evolution 28:58-66.

Simon, H. A. 1962. The architecture of complexity. Proceedings of the American Philosophical Society 106:467-482.

Skillen, J. J., and B. A. Maurer. 2008. The ecological significance of discontinuities in body-mass distributions. Pages 193-218 in C. R. Allen and C. S. Holling, editors. Discontinuities in ecosystems and other complex systems. Columbia University Press, New York, New York, USA.

Smith, T. B., R. K. Wayne, D. J. Girman, and M. W. Bruford. 1997. A role for ecotones in generating rainforest biodiversity. Science 276:1855-1857.

Solé, R. V., and J. Bascompte. 2006. Self-organization in complex ecosystems. Princeton University Press, Princeton, New Jersey, USA.

Stallins, J. A. 2006. Geomorphology and ecology: unifying themes for complex systems in biogeomorphology. Geomorphology 77:207-216. 
Stead, T. K., J. M. Schmid-Araya, P. E. Schmid, and A. G. Hildrew. 2005. The distribution of body size in a stream community: one system, many patterns. Journal of Animal Ecology 74:475-487.

Stow, C. A., C. R. Allen, and A. S. Garmestani. 2007. Evaluating discontinuities in complex systems: toward quantitative measures of resilience. Ecology and Society 12: 26.

Sundstrom, S. M., C. R. Allen, and C. Barichievy. 2012. Species, functional groups, and thresholds in ecological resilience. Conservation Biology 26:305-314.

Szabó, P., and G. Meszéna. 2006. Spatial ecological hierarchies: coexistence on heterogeneous landscapes via scale niche diversification. Ecosystems 9:1009-1016.

Thibault, K. M., E. P. White, A. H. Hurlbert, and S. K. M. Ernest. 2011. Multimodality in the individual size distributions of bird communities. Global Ecology and Biogeography 20:145-153.

Travouillon, K. J., and S. Legendre. 2009. Using cenograms to investigate gaps in mammalian body mass distributions in Australian mammals. Palaeogeography, Palaeoclimatology, Palaeoecology 272:69-84.

Vergnon, R., N. K. Dulvy, and R. P. Freckleton. 2009. Niches versus neutrality: uncovering the drivers of diversity in a species-rich community. Ecology Letters 12:1079-1090.

Vergnon, R., E. H. van Nes, and M. Scheffer. 2012. Emergent neutrality leads to multimodal species abundance distributions. Nature Communications 3:663.

Vié, J.-C., C. Hilton-Taylor, and S. N. Stuart, editors. 2009. Wildlife in a changing world - an analysis of the 2008 IUCN Red List of Threatened Species. IUCN, Gland, Switzerland.

Walker, B., A. Kinzig, and J. Langridge. 1999. Plant attribute diversity, resilience, and ecosystem function: the nature and significance of dominant and minor species. Ecosystems 2: 95-113.

Wang, R., J. A. Dearing, P. G. Langdon, E. Zhang, X. Yang, V. Dakos, and M. Scheffer. 2012a. Flickering gives early warning signals of a critical transition to a eutrophic lake state. Nature 492:419-422.
Wang, S., J. Zhang, and A. B. Lawson. 2012b. A Bayesian normal mixture accelerated failure time spatial model and its application to prostate cancer. Statistical Methods in Medical Research. http://dx.doi.org/10.1177/0962280212466189

Wardwell, D., and C. R. Allen. 2009. Variability in population abundance is associated with thresholds between scaling regimes. Ecology and Society 14:42.

Wardwell, D. A., C. R. Allen, G. D. Peterson, and A. J. Tyre. 2008. A test of the cross-scale resilience model: functional richness in Mediterranean-climate ecosystems. Ecological Complexity 5:165-182.

Warwick, R. M., S. L. Dashfield, and P. J. Somerfield. 2006. The integral structure of a benthic infaunal assemblage. Journal of Experimental Marine Biology and Ecology 330: $12-18$.

Wheatley, M., and C. Johnson. 2009. Factors limiting our understanding of ecological scale. Ecological Complexity 6: $150-159$.

White, E. P., S. K. M. Ernest, A. J. Kerkhoff, and B. J. Enquist. 2007. Relationships between body size and abundance in ecology. Trends in Ecology and Evolution 22:323-330.

Wiens, J. A. 1989. Spatial scaling in ecology. Functional Ecology 3:385-397.

Woodward, G., B. Ebenman, M. Emmerson, J. M. Montoya, J. M. Olesen, A. Valido, and P. H. Warren. 2005. Body size in ecological networks. Trends in Ecology and Evolution 20: 402-409.

Wu, J., and H. Li. 2006. Perspectives and methods of scaling. Pages 17-44 in J. Wu, K. B. Jones, H. Li, and O. Loucks, editors. Scaling and uncertainty analysis in ecology. Springer, Dordrecht, The Netherlands.

Xu, L., T. Hanson, E. Bedrick, and C. Restrepo. 2010. Hypothesis tests on mixture model components with applications in ecology and agriculture. Journal of Agricultural, Biological, and Environmental Statistics 15:308-326.

Yvon-Durocher, G., J. Reiss, J. Blanchard, B. Ebenman, D. M. Perkins, D. C. Reuman, A. Thierry, G. Woodward, and O. L. Petchey. 2011. Across ecosystem comparisons of size structure: methods, approaches and prospects. Oikos 120: $550-563$.

\section{Supplemental Material}

\section{Appendix A}

Table comparing hierarchy theory, panarchy theory, scale domains, and power laws (Ecological Archives E095-055-A1).

\section{Appendix B}

Table describing different methods used to examine the shape of body size distributions (Ecological Archives E095-055-A2). 